\title{
Cleavage of Osteopontin by Matrix Metalloproteinase-12 Modulates Experimental Autoimmune Encephalomyelitis Disease in C57BL/6
} Mice

\author{
Angelika Goncalves DaSilva, ${ }^{*}$ Lucy Liaw, ${ }^{\dagger}$ \\ and V. Wee Yong* \\ From the Department of Clinical Neurosciences and Hotchkiss \\ Brain Institute," University of Calgary, Calgary, Alberta, Canada; \\ and Maine Medical Center Research Institute, ${ }^{\dagger}$ Scarborough, Maine
}

A role for osteopontin (OPN) in promoting disease activity of multiple sclerosis or its animal model experimental autoimmune encephalomyelitis (EAE) has recently been suggested. As the biological activity of OPN is heavily influenced by posttranslational processing, we investigated the capacity of matrix metalloproteinase (MMP)-12 to cleave OPN and determined whether this influenced disease activity. We found that OPN mRNA and protein expression in the spinal cord increased with EAE disease in C57BL/ 6 mice concurrently with MMP-12 expression. A Western blot of EAE and control spinal cords revealed different OPNimmunoreactive bands, with a pattern that was similar to MMP-12 cleavage of recombinant OPN in vitro. In addition, OPN fragments in the spinal cord of EAEafflicted mice were reduced in MMP-12 ${ }^{-/-}$mice compared with wild-type controls. However, examination of $\mathrm{OPN}^{-/-}$mice in short- and long-term experiments revealed no difference in EAE outcomes from wildtype animals. OPN/MMP-12 double null mice were generated, and it was revealed that ${\mathrm{MMP}-12^{-/}}^{-}$mice had a worsening of disease compared with wild-type mice, which returned to wild-type levels in the OPN/ MMP-12 double null mice. These results suggest that EAE disease activity may be modulated by the cleavage of OPN by MMP-12. (Am J Pathol 2010, 177:1448-1458; DOI: 10.2353/ajpath.2010.091081)

Multiple sclerosis (MS) is a disease in which peripheral T cells infiltrate the central nervous system (CNS), where they become re-activated by presentation of CNS antigens by local antigen-presenting cells including micro- glia and dendritic cells to result in demyelination. ${ }^{1-4}$ In attempts to find putative antigens and mediators of disease, studies using gene array analyses revealed that osteopontin (OPN) was highly up-regulated in lesions from patients with MS compared with control subjects. ${ }^{5}$ This result has prompted the investigations of OPN expression and function in MS and experimental autoimmune encephalomyelitis (EAE).

OPN, also known as early $T$ cell activation gene 1 (Eta-1), is a calcium binding phosphorylated acidic glycoprotein. ${ }^{6,7}$ OPN has pluripotent activity and is involved in various biological roles such as extracellular matrix remodeling, tumor invasion, angiogenesis, cell-mediated immunity, and the regulation of urokinase and matrix metalloproteinase (MMP) production. ${ }^{8}$ Chabas et $a l^{5}$ found that OPN was expressed during EAE in various cell types and that $\mathrm{OPN}^{-1-}$ mice had reduced EAE clinical disease, which was associated with a shift toward a Th2 cytokine profile. Jansson et $\mathrm{al}^{9}$ also found that OPN ${ }^{-1-}$ mice had reduced mean maximal score, fewer days of paralyzing disease, and no spontaneous relapses on proteolipid protein-induced EAE. In that study, OPN ${ }^{-1-}$ mice showed reduced production of pro-inflammatory cytokines, interferon- $\gamma$ (IFN- $\gamma$ ), and tumor necrosis factor- $\alpha$. In contrast to these studies, Blom et $\mathrm{al}^{10}$ found no difference between $\mathrm{OPN}^{-1-}$ and wild-type mice for EAE outcomes.

The EAE results sparked an interest in the expression of OPN in MS. Increased levels of OPN protein is reported

Supported by an operating grant from the Canadian Institute of Health Research. A.G.D. was supported by studentships from Alberta Heritage Foundation for Medical Research and the Multiple Sclerosis Society of Canada

Accepted for publication May 27, 2010.

None of the authors disclosed any relevant financial relationships.

Supplemental material for this article can be found on http://ajp. amjpathol.org.

Address reprint requests to V. Wee Yong, Ph.D., University of Calgary, 3330 Hospital Dr, Calgary, Alberta T2N 4N1, Canada. E-mail: vyong@ ucalgary.ca. 
in the serum and plasma in patients with relapsing-remitting MS compared with controls, ${ }^{11-14}$ particularly during relapses, and in their cerebrospinal fluid. ${ }^{15,16}$ However, there is little evidence for a genetic link between OPN and MS disease susceptibility and disease course. ${ }^{11,13,17-20}$ Elevated OPN levels have also been documented by immunohistochemistry around MS lesions ${ }^{21,22}$ although this was not observed by others. ${ }^{23}$ The role that OPN plays in EAE and MS remains uncertain, but a prevailing view is that OPN plays a destructive role during EAE since it reduces apoptosis of effector $T$ cells and because the exogenous administration of recombinant OPN exacerbates EAE clinical disease. ${ }^{24}$

The biological functions of OPN are heavily influenced by posttranslational modifications such as phosphorylation, glycosylation, sulfation, and proteolytic cleavage. ${ }^{25,26}$ Currently, there is very little knowledge about the role that proteolytic cleavage of OPN has on MS and EAE. In other disease states, the cleavage of OPN by MMPs and thrombin alters the biological functions of OPN. ${ }^{27,28}$ For example, OPN that is cleaved by MMP-3 and MMP-7 significantly increases adhesion of tumor cells compared with full length OPN. ${ }^{29}$ Recombinant MMP-12 has been demonstrated to cleave OPN, a protein that strongly influences osteoclasts activities, including attachment, spreading, and resorption. ${ }^{30}$

The family of MMPs is implicated in MS and EAE as several MMP members are elevated in biological samples from these conditions. These include MMP-2, $-3,-8$, $-9,-10,-11,-12,-13,-14$, and $-25 .{ }^{31-38}$ Although the majority of these MMP members appear to have detrimental roles in MS and EAE, ${ }^{39-41} \mathrm{MMP}-12$ is unique since its absence causes an exacerbation in EAE disease scores that is associated with up-regulation of proinflammatory cytokines. ${ }^{31,42}$ Since the MMP-12 $12^{-1-}$ mice phenotype is opposite to the reduced levels of pro-inflammatory cytokines in $\mathrm{OPN}^{-1-}$ mice with $\mathrm{EAE},{ }^{5}$ we considered the possibility that MMP-12 and OPN are inversely associated. In this article, we have tested the hypothesis that MMP-12 processes OPN to reduce its pro-inflammatory potential in EAE. We describe OPN mRNA and protein expression during EAE and have used a combination of MMP-12 and OPN single and OPN/ MMP-12 double null mice to profile their EAE phenotypes.

\section{Materials and Methods}

\section{Disease Induction and EAE Analysis}

$\mathrm{OPN}^{-1-}$ mice on the C57BL/6 strain have been previously described. ${ }^{43}$ Wild-type C57BL/6 mice were purchased from Charles River (Montreal, QC). These two lines were crossed to produce heterozygote $\left(\mathrm{OPN}^{+/-}\right)$ breeders, which were expanded in house, and the offsprings ( $\geq F_{10}$ generation) were used in the experiments while MMP- $12^{-1-}$ mice on the C57BL/6 strain $^{44}$ were purchased from Jackson Laboratory (Bar Harbor, MA) and expanded in house. OPN/MMP-12 $2^{-1-}$ mice on the C57BL/6 strain were generated from breeding OPN ${ }^{-1-}$ and $\mathrm{MMP}_{-12^{-1-}}$ mice to produce a stable line of OPN/
MMP-12 $2^{-/-}$mice ( $\geq F_{5}$ generation). Genotyping con-

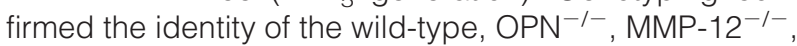
and OPN/MMP-12 $2^{-I-}$ mice (see Supplemental Figure S1 at $h$ ttp://ajp.amjpathol.org). In previous work, we found that the levels of all MMP members analyzed did not differ between naïve wild-type or MMP- $12^{-1-}$ mice. $^{45}$

EAE was induced in female wild-type, OPN ${ }^{-1-}, \mathrm{MMP}$ $12^{-1-}$, or OPN/MMP-12 $2^{-1-}$ mice on C57BL/6 background, aged 8 to 9 weeks, by subcutaneously injecting $100 \mu \mathrm{g}$ myelin oligodendrocyte glycoprotein (MOG) $)_{35-55}$ in Complete Freund's Adjuvant (Difco Laboratories, Detroit, MI). Intraperitoneal pertussis toxin $(0.4 \mu \mathrm{g} / 200 \mu \mathrm{l}$; List Biological Labs, Hornby, ON) was administered on days 0 and 2 .

Mice were assessed by a blinded observer daily by using a 15-point disease score scale, ${ }^{31,46}$ replacing the more commonly used 5-point scale, since the former allowed individual limbs to be tabulated separately to contribute to the overall score. All mice were handled in accordance with the policies outlined by the Canadian Council for Animal Care and the University of Calgary.

Groups of mice were sacrificed at the following time points after immunization with MOG: (1) presymptomatic mice (disease score of 0 ) were sacrificed 5 days after MOG immunization and before clinical signs of disease; (2) disease onset mice (disease score 1 to 3; mostly tail involvement) were sacrificed during the first clinical signs of disease; (3) disease progression (score 4 to 6; involving the tail and hindlimbs) mice were sacrificed during the rise of clinical disability; (4) disease peak (score 7 or more, with forelimb involvement as well) mice were sacrificed during peak clinical disease; and (5) disease stabilization mice were sacrificed postpeak when symptoms were stabilized at a score for 5 days. Other mice were used for long-term behavioral studies and were sacrificed at the end of either 20 or 60 days of observation.

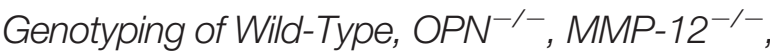 and OPN/MMP-12 ${ }^{-1-}$ Mice}

All mice were genotyped to determine their genetic background. Pups from breeders were genotyped by isolating DNA from ear samples. A total of $1 \mu \mathrm{g}$ of DNA in $4 \mu \mathrm{l}$ was added to $46 \mu$ l of PCR master mix (10× PCR buffer, $10 \mathrm{mmol} / \mathrm{L}$ dNTP, $25 \mathrm{mmol} / \mathrm{L} \mathrm{MgCl}$, $20 \mu \mathrm{mol} / \mathrm{L}$ Neo1360 primer 5'CGTCCTGTAAGTCTGCAGAA-3', OPIn3 primer $\sim 5^{\prime}$-CCATACAGGAAAGAGAGACC-3', OPIn4 primer 5'AACTGTTTTGCTTGCATGC- $3^{\prime}$, $\mathrm{dd}_{2} \mathrm{O}$, and $1.25 \cup \mathrm{Taq}$ polymerase). The PCR was run by using the following conditions: $95^{\circ} \mathrm{C}$ for 1 minute, 40 cycles of $95^{\circ} \mathrm{C}$ for 30 seconds, $53^{\circ} \mathrm{C}$ for 30 seconds, and $72^{\circ} \mathrm{C}$ for 1 minute, $72^{\circ} \mathrm{C}$ for 10 minutes, and $4^{\circ} \mathrm{C}$. The PCR products were resolved on a $1.5 \%$ agarose gel with the following molecular weights: $\mathrm{OPN}^{+/+} 600 \mathrm{bp}, \mathrm{OPN}^{+/-} 600 \mathrm{bp}$, and $500 \mathrm{bp}$ and $\mathrm{OPN}^{-1-} 500 \mathrm{bp}$ (Supplemental Figure S1 at http://ajp.amjpathol.org).

For MMP-12 genotyping a total of 5 ng of DNA in $2 \mu \mathrm{l}$ was added to $12 \mu \mathrm{l}$ of PCR master mix (10× PCR buffer, $10 \mathrm{mmol} / \mathrm{L}$ dNTP, $50 \mathrm{mmol} / \mathrm{L} \mathrm{MgCl}{ }_{2}, 20 \mu \mathrm{mol} / \mathrm{L}$ 
olMR0297 5'-CACGAGACTAGTGAGACGTG-3', $20 \mu \mathrm{mol} / \mathrm{L}$ olMR3207 5'-GCTAGAAGCAACTGGGCAAC-3', 20 rmol/ L oIMR3208 5'-ACATCCTCACGCTTCATGTC-3', dd ${ }_{2} \mathrm{O}$, and $1.25 \mathrm{U}$ Taq polymerase). Two separate PCR reactions were preformed to determine the $\mathrm{MMP}^{-12^{+/+}}$ (olMR3208 and olMR3207) and MMP-12-1- (olMR3208 and olMR0297) PCR products. The PCR was run by using the following conditions: $94^{\circ} \mathrm{C}$ for 3 minutes, 35 cycles of $94^{\circ} \mathrm{C}$ for 30 seconds, $65^{\circ} \mathrm{C}$ for 1 minute, and $72^{\circ} \mathrm{C}$ for 1 minute, followed by $72^{\circ} \mathrm{C}$ for 2 minutes. The PCR products were resolved on a $1 \%$ agarose gel with the following molecular weights: MMP- $12^{+/+} 1064 \mathrm{bp}, \mathrm{MMP}^{-12^{+/-}}$ 1064 and $1500 \mathrm{bp}$, and MMP-12 ${ }^{-/-} 1500$ bp fragments (see Supplemental Figure S1 at http://ajp.amjpathol.org).

\section{Real-Time PCR of cDNA from Thoracic Spinal Cords of EAE C57BL/6 Mice}

Mice were sacrificed via an overdose of ketamine/xylazine (Bimeda-MTC Animal Health Inc., Cambridge, ON) and bled by an incision to the atrium of the heart. Immediately after bleeding, the thoracic spinal cord was removed and placed into $1 \mathrm{ml}$ of TRIzol (Invitrogen, Missisauga, ON), homogenized via syringe, flashed frozen in liquid nitrogen, and stored at $-80^{\circ} \mathrm{C}$ until further RNA processing as described by the manufacturer. Only samples with an $A_{260 / 280}$ ratio $>1.60$ were used for subsequent analysis. A total of $1 \mu \mathrm{g}$ of RNA was used from each sample evaluated and CDNA was made. RNA was treated with $R Q 1$ RNase-Free DNase at $37^{\circ} \mathrm{C}$ for 45 minutes and $65^{\circ} \mathrm{C}$ for 10 minutes. After DNase treatment, the cDNA master mix $(5 \times$ first strand buffer, $0.1 \mathrm{M}$ DTT, 5 $\mathrm{mmol} / \mathrm{L}$ dNTPs, random primers (d(N)6), $40 \mathrm{U} / \mathrm{ml}$ RNAsin/ RNase out, and $200 \mathrm{U} / \mathrm{ml}$ superscript reverse transcriptase) was added to each sample. Samples were incubated by using the following protocol: $37^{\circ} \mathrm{C}$ for $1 \frac{1}{2}$ hours, $70^{\circ} \mathrm{C}$ for 5 minutes, and then $4^{\circ} \mathrm{C}$. cDNA was diluted to a final volume of $100 \mu \mathrm{l}$ and stored at $-20^{\circ} \mathrm{C}$ until further use.

Real-time PCR reactions were performed by using SYBR green, and relative fold expression values were calculated based on housekeeping genes (glyceraldehyde-3-phosphate dehydrogenase [GAPDH]) by using the comparative $\mathrm{C}_{\mathrm{T}}$ method for relative quantization using $2^{-} \Delta \Delta \mathrm{C}_{\mathrm{T}}$. For each sample, $5 \mu \mathrm{l}$ of CDNA was added to 20 $\mu$ l of the PCR master mix (40 mmol/L Tris- $\mathrm{HCl} \mathrm{pH} \mathrm{8.4,} 100$ $\mathrm{mmol} / \mathrm{L} \mathrm{KCl}, 6 \mathrm{mmol} / \mathrm{L} \mathrm{MgCl}_{2}, 400 \mu \mathrm{mol} / \mathrm{L} \mathrm{dGTP}, 400$ $\mu \mathrm{mol} / \mathrm{L}$ dTTP, $400 \mu \mathrm{mol} / \mathrm{L}$ dCTP, $400 \mu \mathrm{mol} / \mathrm{L}$ dATP, $10 \%$ Glycerol, 0.1\% Tween 20, SYBR Green I [1/50,000], Fluorescein $[1 / 10,000], 5 \mu \mathrm{mol} / \mathrm{L}$ primer mix, and Taq polymerase) and was incubated by using the following conditions: $95^{\circ} \mathrm{C}$ for 5 minutes, 45 cycles of $95^{\circ} \mathrm{C}$ for 30 seconds, $55^{\circ} \mathrm{C}$ to $60^{\circ} \mathrm{C}$ for 30 seconds, and $72^{\circ} \mathrm{C}$ for 30 seconds, $72^{\circ} \mathrm{C}$ for 5 minutes followed by a melt curve gradient. OPN forward: 5'-ATTTGCTTTTGCCTGTTTGG3'; OPN reverse: 5'-CCTTTCCGTTGTTGTCCTGA-3'. GAPDH forward: 5'-GGCATTGCTCTCAATGACAA-3'; GAPDH reverse: 5'- TGTGAGGGAGATGCTCAGTG-3' .

\section{Histology of Tissue from Control and EAE Mice}

Mice were sacrificed, bled by aortic puncture for 5 minutes while the heart was pumping, and whole spinal cords were removed and fixed by submersion in 10\% buffered formalin (Surgipath Canada Inc., Winnipeg, MB) for 24 hours. Spinal cords were divided into thoracic and lumbar sacral portion and embedded in paraffin blocks. Thoracic cords were cut longitudinally on a microtome and four adjacent 6- $\mu \mathrm{m}$ thick sections were placed on glass slides (Fisher, MI) for a total of four series of 48 sections from each animal. The first series of sections was then processed for H\&E and Luxol fast blue.

For histology, slides were warmed at $60^{\circ} \mathrm{C}$ for 1 hour, deparaffinized through a series of ethanol steps and then placed in luxol fast blue (solvent 38; Sigma, St. Louis, $\mathrm{MO}$ ) at $60^{\circ} \mathrm{C}$ for 3 hours. Slides were then placed in $95 \%$ ethanol, followed by water and then $0.05 \%$ lithium carbonate before being placed in $70 \%$ ethanol. Once the appropriate myelin color differentiation was achieved, slides were placed in hematoxylin (EMD, San Diego, CA) for 4 minutes. Slides were then sequentially dipped in $1 \%$ acid alcohol and ammonia water, with water washes in between, and then rinsed in water again, followed by $70 \%$ ethanol and $95 \%$ ethanol before being dipped in alcoholic eosin (EMD). Slides were then passed through a series of ethanol steps before being coverslipped by using acrytol (Surgipath Canada Inc.). Images were captured by using an Olympus $\mathrm{BH}-2$ microscope (Olympus, Port Moody, BC) and QCapture Pro software (version 5.1.1.14; Media Cybernetics Inc., Bethesda, MD).

For semiquantitative assessment of the extent of inflammation in the spinal cord, all stained longitudinal sections from the same coded mouse were first evaluated by using the scoring system outlined in Goncalves DaSilva and Yong. ${ }^{42}$ In this regard, the location (pial versus parenchymal) and number of inflammatory aggregates per section were documented, with parenchymal inflammation and larger and higher number of aggregates being ascribed greater inflammation scores.

Finally, the number of inflammatory lesions/aggregates was counted per longitudinal section. Six different sections per animal were examined by a blinded observer and the average number of lesions per section was documented.

\section{Protein Extraction from Lumbar Sacral Spinal Cords of Mice}

Protein was isolated from lumbar sacral spinal cords by using a lysis buffer $(50 \mathrm{mmol} / \mathrm{L}$ Tris- $\mathrm{HCl}, 150 \mathrm{mmol} / \mathrm{L}$ $\mathrm{NaCl}, 1 \mathrm{mmol} / \mathrm{L}$ EGTA, $1 \% \mathrm{NP}-40,0.5 \%$ sodium deoxycholate, and $1 \%$ proteinase inhibitors [Roche, Mississauga, ON]) and homogenized. Samples were spun down at $3000 \mathrm{rpm}$ and supernatants were removed. Protein content in the supernatants was measured by the Bradford assay and $20 \mu \mathrm{g}$ was used for western blots; these extracts are referred to as crude protein extracts. In other experiments, a total of $1500 \mu \mathrm{g}$ of crude protein extract was used for further glycoprotein extraction via wheat germ agglutinin (WGA) beads. WGA beads were 
equilibrated in lysis buffer for 30 minutes at $4^{\circ} \mathrm{C}$ by rotation before adding protein homogenates. The homogenate-WGA slurry was then incubated via rotation overnight at $4^{\circ} \mathrm{C}$. The following day, samples were spun down at $3000 \mathrm{rpm}$, and supernatants were removed and washed three times with Tris-buffered solution containing $0.1 \%$ Triton-X 100 and protease inhibitors. After the final wash, proteins were eluted after incubation at $4^{\circ} \mathrm{C}$ via rotation for 10 minutes in Tris-buffered solution containing $0.1 \%$ Triton- $X$ 100, 0.3M N-acetyl-glucosamine, and protease inhibitors.

Samples (approximately $20 \mu \mathrm{g}$ ) were run on a reducing $12 \%$ SDS-acrylamide gel, and the proteins were transferred to polyvinylidene difluoride (PVDF) membranes (Millipore Inc., Bedford, MA). The PVDF membranes were probed with primary antibodies against mouse OPN (R\&D Systems, Burlington, ON; 0.5 $\mu \mathrm{g} / \mathrm{ml})$. Secondary peroxidase-conjugated donkey anti-goat IgG (Jackson ImmunoResearch, West Grove, PA; 1/10,000) together with enhanced chemiluminescence (ECL) chemiluminescence (Amersham Biosciences, Piscataway, NJ) was used for the detection of the primary antibodies. All blots were also examined for nonspecific reactivity via the use of secondary antibody controls, and by the omission of the primary antibody.

\section{In Vitro Examination of OPN Cleavage by MMP-12}

Purified human osteopontin (100 ng; Chemicon, Temecula, CA) was incubated with $5 \mu$ l activated full length human hemopexin containing MMP-12 (hemo-MMP-12; R\&D Systems) in reaction buffer containing $50 \mathrm{mmol} / \mathrm{L}$ Tris-HCL pH 7.6, $150 \mathrm{mmol} / \mathrm{L} \mathrm{NaCl}_{2}, 10 \mathrm{mmol} / \mathrm{L} \mathrm{CaCl}{ }_{2}$, and $0.01 \mathrm{mmol} / \mathrm{L} \mathrm{ZnCl}_{2}$ for either 15 minutes, 1 hour, 3 hours, or 24 hours at $37^{\circ} \mathrm{C}$. Alternatively, another set of identical reactions was run under the same conditions as outlined above with the exception of the addition of 1 $\mu \mathrm{mol} / \mathrm{L}$ of BB94, a metalloproteinase inhibitor, to each condition (British Biotech, Morristown, NJ). The reactions were fractionated on a reducing $12 \%$ SDS-acrylamide gel and the proteins were transferred to PVDF membranes (Millipore Inc.). The PVDF membranes were probed with primary antibodies against both human and mouse OPN $(0.5 \mu \mathrm{g} / \mathrm{ml}, \mathrm{R} \& \mathrm{D}$ Systems). Secondary peroxidase-conjugated donkey anti-goat IgG (1/10,000; Jackson ImmunoResearch) together with ECL chemiluminescence (Amersham Biosciences) was used for the detection of the primary antibodies.

\section{EDMAN Sequencing}

OPN cleavage by MMP-12 was preformed as described above, and samples were isolated and submitted for EDMAN sequencing at a commercial facility (Sainte-Foy, Quebec). N-terminal sequencing was performed on the MMP-12 cleaved OPN fragments and major amino acids were identified, which were then used to design OPN peptides that were added to human peripheral blood mononuclear cells in culture (see next section).

\section{Examination of OPN Peptide Fragments for Their Ability to Influence T Cells}

Blood samples were collected in heparinized tubes from healthy donors. Blood samples were mixed (1:1) with PBS and then layered on top of Ficoll (GE Health Care Bioscience, Uppsala, Sweden). The buffy layer containing the peripheral blood mononuclear cells was removed and washed two times in PBS before plating onto $\alpha \mathrm{CD} 3$ precoated flat bottom plates $(10 \mathrm{ng} / \mathrm{ml}$ ) at a density of 200,000 cells/100 $\mu$ l in medium containing $1 \%$ human serum (Invitrogen). At the time of plating, 2 $\mu \mathrm{mol} / \mathrm{L}$ SVVYG or IPVKQ was added to the cells, which were then incubated for 72 hours at $37^{\circ} \mathrm{C}$ and $5 \% \mathrm{CO}_{2}$. Conditioned medium was removed and used directly for human interleukin (IL)-17 (Biosource, Belgium) and IFN- $\gamma$ (Invitrogen) enzyme-linked immunosorbent assay as described by the manufacturers.

\section{RNase Protection Assay}

Multiprobe RNase protection assay was done to analyze simultaneously the expression of several MMP members during EAE. We used the thoracic spinal cord of EAE $\mathrm{MMP}-12^{+/+}$and $\mathrm{MMP}-12^{-/-}$mice. After RNA extraction, $5 \mu \mathrm{g}$ of total RNA was used for each sample. The mouse MMP multiprobe set was obtained from PharMingen (Mississauga, ON). RNase protection assay was performed as described previously in Larsen. ${ }^{47}$

\section{Statistical Analysis}

Statistical analysis was performed by using Prism 5 (version 5.0; GraphPad Software Inc., San Diego, CA). Statistical differences between groups with respect to disease onset, mean peak score, mean average disease score, mean cumulative disease, and histopathology were evaluated by using a nonparametric analysis MannWhitney U-test. Statistical differences between groups with respect to daily clinical disease were evaluated by using repeated measures two-way analysis of variance and Bonferroni posthoc analyses. Statistical differences between groups with respect to OPN protein expression were evaluated by using repeated measures one-way analysis of variance and Tukey's posthoc analyses. Significance was set at $P<0.05$.

\section{Results}

\section{OPN Expression during EAE in Female C57BL/6 Mice}

Female wild-type C57BL/6 mice were induced for EAE with $\mathrm{MOG}_{35-55}$ and the temporal expression of OPN in the spinal cord was examined. OPN mRNA levels increased with EAE particularly at the progression phase and it resolved thereafter (Figure 1A) ${ }^{28,42}$ MMP-12 transcript was also determined and since we have described its elevation in the spinal cord of EAE in another article 

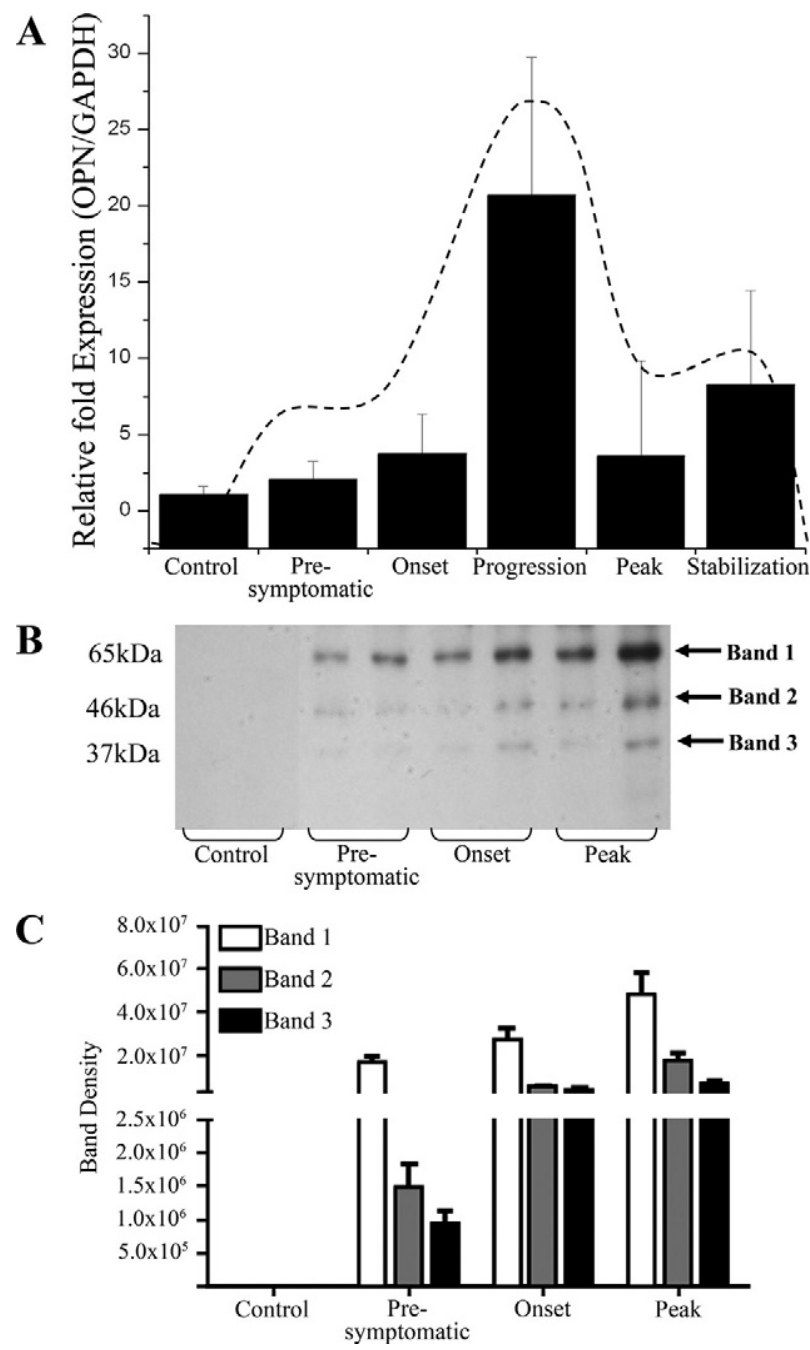

Figure 1. The expression of OPN in EAE is disease-stage dependent and different protein forms occur with EAE progression. A: Expression of transcripts encoding OPN. Values are mean \pm SEM of expression of transcript normalized to that of a house keeping gene, GAPDH, using the comparative $\mathrm{C}_{\mathrm{T}}$ method for relative quantification using $2^{-} \Delta \Delta \mathrm{C}_{\mathrm{T}}$. There are five $\mathrm{C} 57 \mathrm{BL} / 6$ mice per histogram. The average disease score (mean \pm SEM) of mice at presymptomatic stage, onset, progression, peak, and stabilization were respectively $0,1.6 \pm 0.9,4.8 \pm 0.8,8.8 \pm 0.8$, and $8.0 \pm 0.0$. Note that the increase in OPN transcripts follows a profile that is similar to that which we have reported for MMP-12 (shown here as a dashed line). ${ }^{42,48} \mathbf{B}$ : Western blot of mouse spinal cord detects three OPN-immunoreactive bands (arrows) during EAE from WGA extracted samples. All three bands are upregulated during EAE compared with control samples. Two samples per disease stage are displayed in the gel in $\mathbf{B}$, and the bars in $\mathbf{C}$ represent the mean \pm SEM of these two specimens, and two additional mice/disease stage from another experiment (final $N=4$ mice per group). The $y$-axes for the plots in $\mathbf{C}$ are relative densitometry reading.

that focused on MMP-12 activity in EAE, ${ }^{48}$ we have outlined the changes of MMP-12 here (Figure 1A, dashed line); ${ }^{42,48}$ the data show that the elevation of MMP-12 and OPN mRNA expression in the spinal cord coincided temporally.

The protein expression of OPN in the spinal cord was also determined. OPN ( $\sim 65 \mathrm{kDa})$ was readily apparent in EAE-induced wild-type mice even at the presymptomatic stage; smaller fragments $(\sim 46$ and $\sim 37 \mathrm{kDa})$ were also seen in EAE (Figure 1, B and C). ${ }^{42,48}$ OPN-immunoreactive bands were most abundant at peak disease, trailing

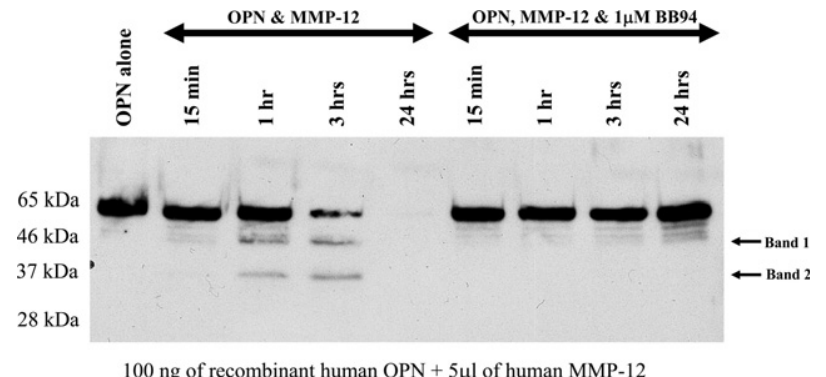

Figure 2. The incubation of recombinant human OPN with human MMP-12 results in the formation of two major cleavage products in a time dependent manner. After 1 hour incubation with MMP-12 (containing hemopexin and catalytic domains), two fragments (arrow) of approximately equal sizes to those of Figure 1 appear; after 24 hours incubation, the full-length protein and all fragments have been digested. The cleavage of OPN is inhibited in the presence of $1 \mu \mathrm{mol} / \mathrm{L}$ BB94. This is a representative blot of five separate experiments. We note that although the size $(\mathrm{kDa})$ of the fragments appears identical to that from the EAE spinal cords in Figure 1, we have no evidence that the fragments from human and mouse specimens are indeed identical given the relatively crude nature of sizing by molecular weight ladders in gel.

the peak in OPN mRNA (Figure $1 \mathrm{~A})^{42,48}$ that is seen at the progression phase of EAE.

\section{Posttranslational Modification of OPN by MMP- 12 in Vitro}

Given the correspondence of temporal expression of transcripts encoding MMP-12 and OPN in the spinal cord of EAE mice, there is the possibility that MMP-12 could process OPN in vivo. Thus, we examined whether OPN was a substrate for MMP-12 cleavage. To address this, we resorted first to biochemical reactions in vitro, and specifically examined whether hemo-MMP-12 (containing the hemopexin domain) could cleave recombinant human OPN in a time-dependent manner. After 1 hour of incubation with hemo-MMP-12, OPN was degraded into two smaller molecular weight fragments (Figure 2). It was observed that the cleaved products of OPN by MMP-12 in vitro were similar in molecular size to those observed in vivo (Figure 1) ${ }^{42,48}$ during EAE. By 3 hours we found that hemo-MMP-12 cleaved OPN further, whereas at 24 hours there was complete degradation of OPN with no fragments visible. The cleavage of OPN by hemo-MMP-12 was completely inhibited in the presence of BB94, an inhibitor of MMP activity.

We addressed whether other MMPs could also cleave OPN. Using the above biochemical reaction, we found that MMP-3 could cleave OPN to produce fragments that are of similar sizes to those produced by MMP-12; in contrast, we could not obtain evidence of reproducible processing of OPN by MMP-1, $-2,-7,-9,-10$, and -13 (data not shown).

\section{Properties of Altered OPN Fragments in Culture}

To investigate whether the cleavage of OPN by MMP-12 produced fragments that have functions for immune cell subsets, we first collected the products of OPN cleavage for mass spectrometry. We identified fragments corresponding to short peptide sequences (see Supplemental 
Figure S2 at http://ajp.amjpathol.org) and two of the sequences (SVVYG and IPVKQ) were synthesized and applied to human T cells when left unactivated, or activated with anti-CD3 antibody. After 3 days, while levels of IFN- $\gamma$ were unaltered, IL-17 was increased by the peptide sequences. IL-17 is a cytokine associated with a pro-inflammatory $\mathrm{T}$ helper 17 subset. These results suggest that processing of OPN by MMP-12 resulted in fragments with immune-stimulating effects.

\section{Altered Processing of OPN in MMP-12-1- Mice}

To determine whether OPN expression and subsequent cleavage by MMP-12 occurred in vivo, we examined if there were any changes in OPN expression in EAE-afflicted MMP-12 $2^{-1-}$ compared with EAE-wild-type mice. We found that OPN mRNA expression did not differ significantly in $\mathrm{MMP}-12^{-/-}$mice during EAE in comparison with wild-type mice (Figure 3A). Similarly, we did not find significant changes in the protein content of the full length OPN in either the crude protein extract or the WGA extract of spinal cords from EAE-afflicted wild-type or MMP$12^{-1-}$ mice (Figure 3, B and C). However, the 46, 37, and $28 \mathrm{kDa}$ bands were all significantly reduced in the MMP$12^{-1-}$ samples compared with wild-type mice.

Besides the full length $65 \mathrm{kDa}$ species, we were only able to detect another form of OPN in the WGA extract: the $58 \mathrm{kDa}$ band. The latter was significantly higher in MMP-12 ${ }^{-1-}$ mice during EAE compared with wild-type, which was not observed in analyses of the crude protein extract. Overall, these results suggest that there is less processing of OPN into fragments during EAE in the context of MMP-12 deficiency.

Our previous report ${ }^{45}$ revealed that the levels of all MMP members analyzed did not differ between naïve wild-type or MMP-12 $2^{-1-}$ mice, or when these mice were subjected to an intracerebral hemorrhage insult. We determined if this was also the case in EAE-afflicted mice. Using the spinal cord of mice with different degrees of EAE clinical severity, and RNase protection assay to detect multiple MMPs as well as their tissue inhibitors of metalloproteinases, we found no evidence of obvious alteration of levels of MMPs (MMP-7, $-8,-9$, or -13 ) or tissue inhibitors of metalloproteinases (tissue inhibitor of metalloproteinase-1, -2 , and -3 ), with the exception of MMP-3, which was elevated in wild-type but not MMP$12^{-1-}$ mice (see Supplemental Figure S3 at http://ajp. amjpathol.org). That MMP-3 was not elevated in MMP$12^{-1-}$ mice during EAE is important because MMP-3 can also cleave OPN as noted above, but its absence in EAE in $\mathrm{MMP}-12^{-1-}$ mice indicates that it was not able to compensate for loss of MMP-12.

\section{Chronic EAE in OPN ${ }^{-/-}, M_{M P-12}^{-/-}$, and Double Null Mice}

We evaluated the phenotype of EAE in mice of different genotypes. In our first experiment, chronic EAE was induced in female mice by using $\mathrm{MOG}_{35-55}$ and mice were observed for 20 days. There was no significant difference
A

B
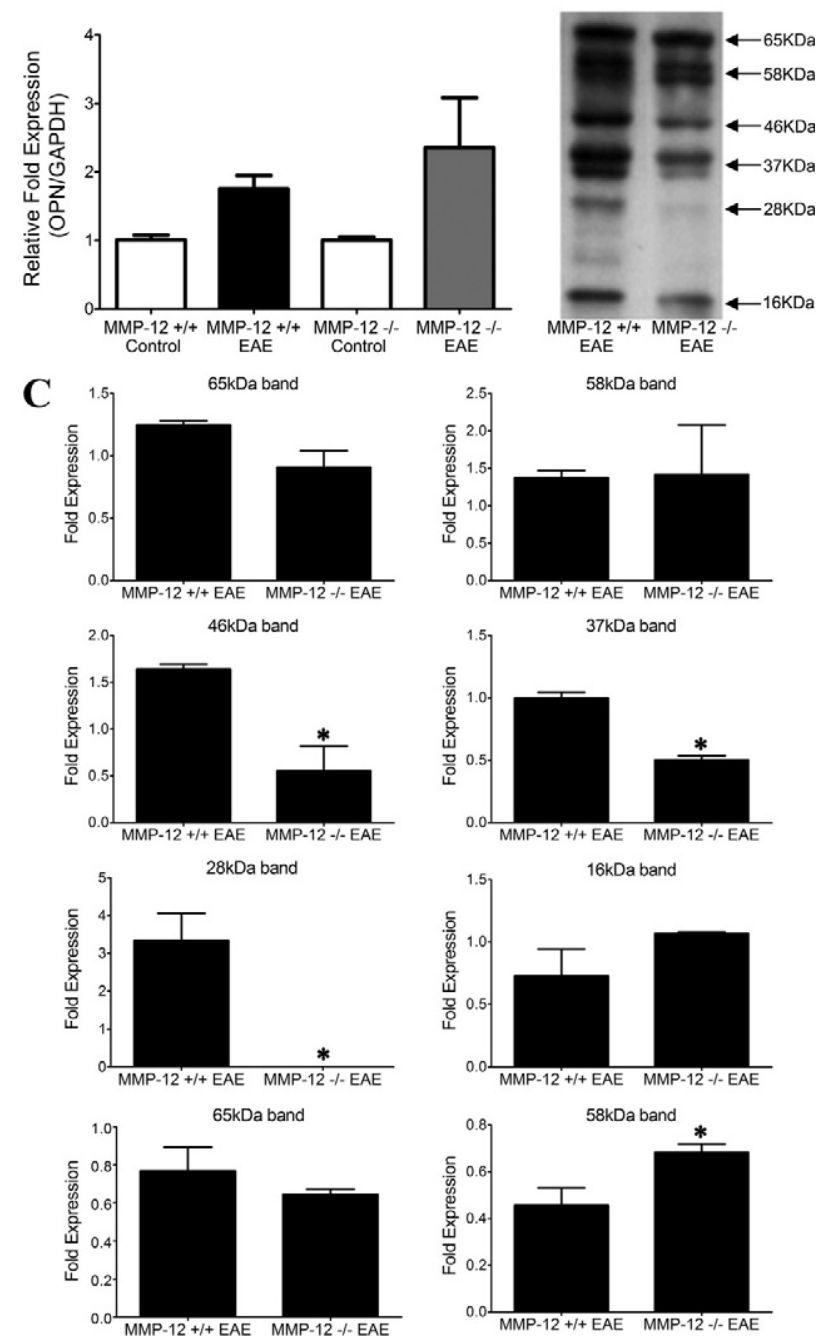

Figure 3. The expression of OPN in $\mathrm{MMP}-12^{+/+}$and $\mathrm{MMP}-12^{-/-}$mice changes slightly with EAE. A: Expression of transcripts encoding OPN. Values are mean \pm SEM of expression of transcript normalized to that of a house keeping gene, GAPDH. There are four C57BL/6 mice per control histogram and six C57BL/6 mice per EAE histogram. Samples were collected from mice at peak disease (clinical score of $>8$ ). There was no statistical significant difference in OPN transcripts between $\mathrm{MMP}-12^{-/-}$and MMP$12^{+/+}$mice. B: A representative Western blot for OPN in crude extract of EAE-afflicted spinal cord at peak disease from a wild-type or MMP-12 ${ }^{-1}$ mouse. C: Quantification of some of the bands (crude protein extract, top six panels; WGA extract, bottom two panels) detected by the anti-OPN antibody in $\mathbf{B}$, across four mice per genotype and where spinal cord samples were obtained at peak disease. Although several bands were apparent in crude protein extracts, where only some were quantitated to highlight differences between genotypes, WGA extract of OPN showed only two dominant bands with the $58 \mathrm{kDa}$ band changing significantly between groups. Values are mean \pm SEM. ${ }^{*} P<0.05, t$-test

between the wild-type and $\mathrm{OPN}^{-1-}$ mice in the overall clinical disease course (Figure 4A), time of onset of clinical signs (Figure 4B), peak disease score attained by individual mice (Figure 4C), and the cumulative score per mouse over the course of the 20 days (data not shown).

We examined the thoracic spinal cords from OPN ${ }^{+/+}$ and OPN ${ }^{-1-}$ mice sacrificed at day 20 by using Luxol fast blue and H\&E to determine whether there were any differences in pathology. Using a semiquantitative classification system, ${ }^{42}$ we found that the lesions between the 
A

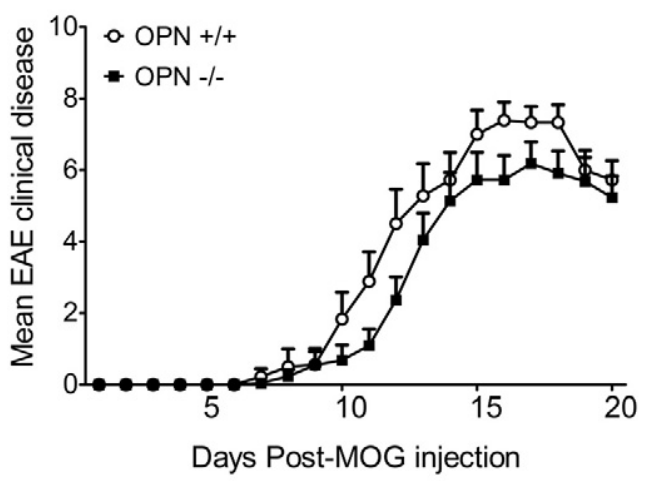

B Disease onset

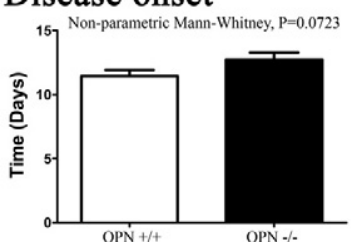

C Peak disease score

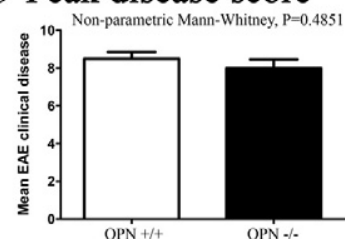

Figure 4. Wild-type and $\mathrm{OPN}^{-/-}$mice have similar EAE profiles over 20 days of observation. A: Daily average EAE score. Repeated measures twoway analysis of variance and posthoc Bonferroni tests did not show differences between the OPN ${ }^{+/+}(n=18)$ and $\mathrm{OPN}^{-/-}(n=21)$ mice. B: Disease onset, where no significant difference between wild-type and $\mathrm{OPN}^{-1-}$ mice was found. C: Peak disease score, showing that there is no significant difference between the two groups. Values are mean \pm SEM. Nonparametric Mann-Whitney test was used in $\mathbf{B}$ and $\mathbf{C}\left(\mathrm{OPN}^{+/+}\right.$mice, $N=$ 18 ; $\mathrm{OPN}^{-/-}, N=21$ )

$\mathrm{OPN}^{+/+}$and $\mathrm{OPN}^{-1-}$ mice were similar in appearance and that there was no significant difference in the average number of lesions (Figure $5 \mathrm{~A})^{42}$ or extent of inflammation (Figure $5 \mathrm{~B})^{42}$ between the groups. Thus, in agreement with the clinical score, we found there was no significant histological difference between wild-type and $\mathrm{OPN}^{-1-}$ mice.

Although the above work documents that the absence of OPN alone does not affect EAE clinical disease in short-term experiments, we addressed if this were also the case in chronic experiments. Moreover, it was of interest to address whether EAE activity in $\mathrm{OPN}^{-1-}$ mice could be altered in the background of MMP-12 deficiency, given that MMP-12 can process OPN into fragments (Figures 2 and 3). Thus, we examined the EAE phenotype of OPN ${ }^{-1-}, \mathrm{MMP}^{-12^{-1-}}$, and OPN/MMP-12 double null mice after $\mathrm{MOG}_{35-55}$ immunization, and mice were examined daily for 60 days. We found that all genotypes commenced disease around the same time (Figure $6, \mathrm{~A}$ and $\mathrm{B})$. MMP-12 $2^{-1-}$ mice reached a significantly higher peak disease severity $(11.3 \pm 0.5)$ compared with $\mathrm{OPN}^{-1-}(9.2 \pm 0.4)$, OPN/MMP-12 $2^{-1-}(8.1 \pm 0.8)$, and wild-type $(9.3 \pm 0.6)$ mice (Figure $6 \mathrm{C})$. In agreement with our previous report, ${ }^{42}$ we also found that $\mathrm{MMP}^{-12^{-/-}}$ mice had significantly higher mean clinical disease scores and cumulative disease score $(6.6 \pm 0.3 ; 415.7 \pm$ 19.3, respectively) compared with $\mathrm{OPN}^{-1-}(5.7 \pm 0.3$; $371.9 \pm 19.1)$, OPN/MMP-12 ${ }^{-1-}(3.0 \pm 0.5 ; 193.8 \pm$ 30.6), and wild-type $(4.6 \pm 1.0 ; 289.3 \pm 61.6)$ mice (Figure 6, A and D). Interestingly, we found that the

\section{A Lesion number}

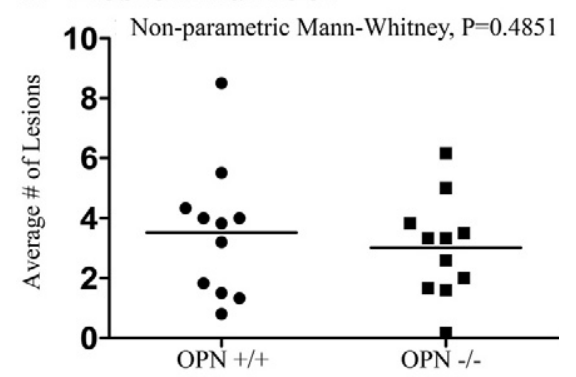

B Inflammation score

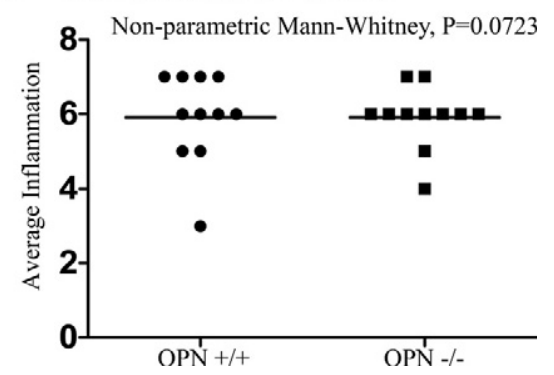

Figure 5. The degree of neuropathology is similar between wild-type and $\mathrm{OPN}^{-/-}$mice at the end of the EAE observation period (20 days). A: The lesions number, referring to the average number of inflammatory lesions that are encountered within six longitudinal spinal cord sections of a given mouse, was similar between wild-type and $\mathrm{OPN}^{-1-}$ mice. B: Inflammation score of the spinal cords of mice, assessed in sections stained with Luxol fast blue/H\&E and scored blindly as described in Goncalves DaSilva and Yong, ${ }^{42}$ is similar between wild-type and $\mathrm{OPN}^{-1-}$ mice. Control naïve spinal cords from all genotypes were absent of demyelination and infiltrates, and we did not observe any gross anatomical or myelin structure abnormalities between the genotypes. Individual values are plotted and the bar represents the mean for the group. Nonparametric Mann-Whitney tests did not show significance; $P>0.05$. There were 11 wild-type cords analyzed, and 11 from $\mathrm{OPN}^{-/-}$mice.

absence of both OPN and MMP-12 resulted in a greater reduction in the average and cumulative score than for either single null alone. Thus, in the absence of MMP-12 there is an exacerbation of EAE, which is abated in the OPN/MMP-12 double null mice.

It is important to note that for the EAE experiment depicted in Figure 6, we used a large group of mice born at a similar time and for which EAE was induced without prior knowledge of the animal's genotype. Only after the EAE experiment was completed (day 60) was the genotyping performed. This approach was taken to minimize bias and to maximize randomization. One outcome was that the size of each group could not be controlled resulting in an unequal group size of 5 to 19 for the genotypes when unblinding occurred.

Histological examination of tissue taken from mice on the 60th day of EAE showed a trend toward a decrease in the lesion number and the inflammatory score in the OPN/MMP-12 $12^{-1-}$ mice, but this was not significantly different from the other groups (Figure 7, A and B).

\section{Discussion}

We found that during EAE, the increase in OPN mRNA corresponded with the expression of MMP-12 transcript. Furthermore, there was altered protein expression for 
$\mathbf{A}$

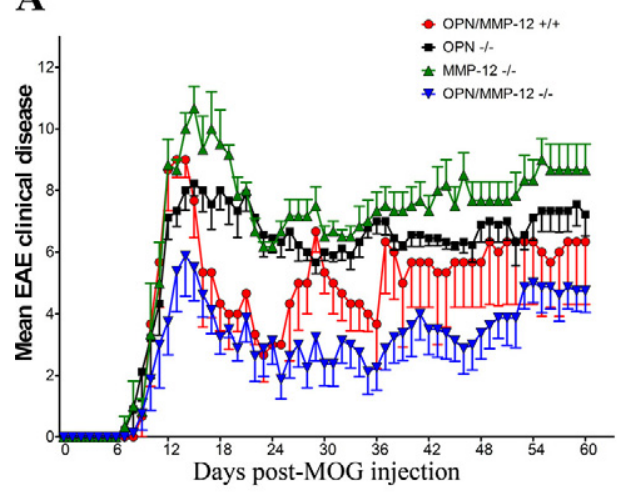

C Peak disease score

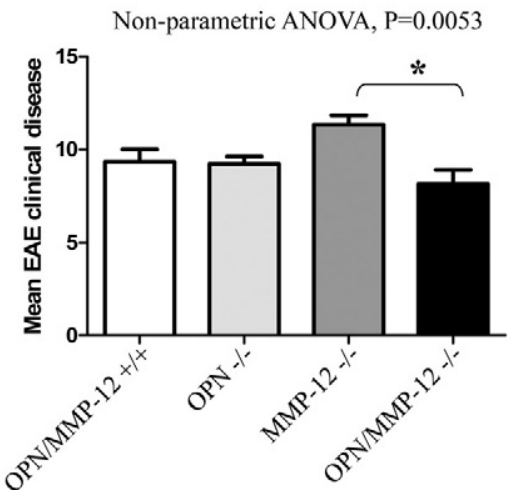

B Disease onset

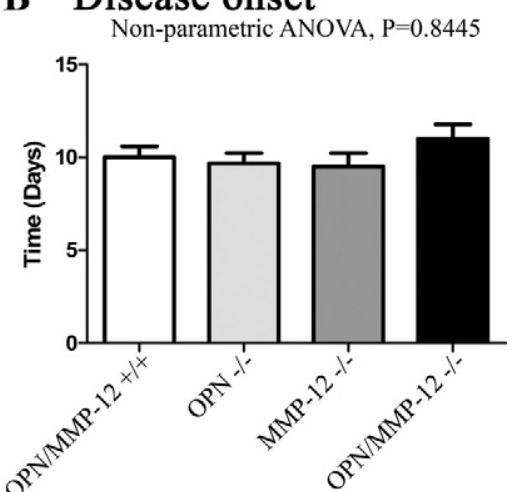

D Average cumulative score over 60 days

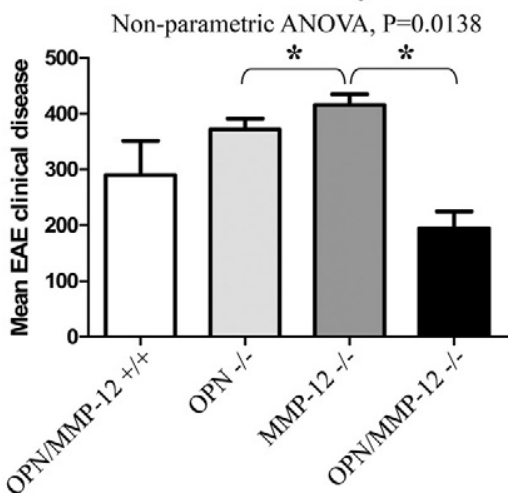

Figure 6. EAE profiles in wild-type, $\mathrm{OPN}^{-/-}$ MMP- $12^{-/-}$, and OPN/MMP- $12^{-/-}$mice over 60 days of observation. A: OPN/MMP-12 $2^{-1-}$ double null mice had reduced disease in comparison with other groups. Values are mean \pm SEM. Repeated measures two-way analysis of variance were significant $(P<0.05)$ across the four group comparisons. Wild-type, $N=12$; $\mathrm{OPN}^{-1-}, N=19$; MMP$12^{-/-}, N=5$; and OPN/MMP- $12^{-/-}, N=8$. B: Disease onset, where there is no significant difference between wild-type, $\mathrm{OPN}^{-/-}, \mathrm{MMP}^{-12^{-/}}$ and OPN/MMP-12 $2^{-1-}$ mice. C: Peak disease score, where MMP-12 $2^{-/-}$mice have a higher score than OPN/MMP-12 ${ }^{-/-}$mice. D: The higher cumulative score in MMP-12 $2^{-/-}$mice compared with wildtype level $(P<0.05)$ is normalized in the OPN/ MMP- $12^{-1-}$ mice. Values are mean \pm SEM. ${ }^{*} P<$ 0.05 (nonparametric one-way analysis of variance with Dunn's Multiple Comparison posthoc test) OPN/MMP- $12^{+/+}, N=12 ; \mathrm{OPN}^{-/-}, N=19 ;$ MMP- $12^{-/-}, N=5$; and OPN/MMP- $12^{-/-}, N=8$. different forms of OPN with EAE. We note that there were more OPN-immunoreactive species detected in the EAE animals in Figure 3 compared with another batch of EAE specimens that are shown in Figure 1, likely reflecting differences between experiments in tissue processing, the Western blot conditions, the length of exposure to the detection reagents, and other unknown variables. As the intent of this article was not to fully resolve all of the processed forms of OPN in EAE, but rather whether MMP-12 could process OPN, we await future opportunities to fully characterize OPN products during neuroinflammation. In our work, a relationship between MMP-12 and OPN is supported by the data that (1) OPN is processed by MMP-12 in vitro (Figure 2), (2) the cleavage products of OPN following MMP-12 processing are similar in molecular sizes to OPN fragments found in EAE (Figures 1 and 2), (3) EAE-afflicted MMP-12 $2^{-1-}$ mice have a reduced amount of OPN fragments in the inflamed spinal cord (Figure 3), and (4) the exacerbated EAE clinical disease in $\mathrm{MMP}-12^{-1-}$ mice was returned to wild-type control levels when OPN was simultaneously absent (Figure 6). These results shed light on the mechanisms by which MMP-12 is beneficial in EAE, and they highlight the idea that different forms of OPN expressed in the spinal cord of EAE afflicted mice may affect disease activity. The requirement for OPN in EAE is somewhat subtle, since $\mathrm{OPN}^{-1-}$ mice did not have altered susceptibility to EAE compared with wild-type controls in our experiments.

We note that although the clinical severity of MMP-12 and OPN double null mice was significantly reduced compared with that of the other groups (Figure 6), the extent of spinal cord inflammation (Figure 7) only trended toward a reduction and was not statistically decreased relative to the histology of the other genotypes. We believe that this reflects the insensitivity of the inflammation scores since a change of one ordinal does require substantial alterations to have been incurred in tissue histology.

OPN has become a molecule of interest in the pathogenesis of MS and EAE ever since Chabas et $\mathrm{al}^{5}$ found in microarray analyses of MS plaques that it was the second most abundantly up-regulated gene product compared with control samples, after $\alpha$-B-crystallin. The pathogenic role of OPN was inferred from EAE experiments, which showed that although both OPN ${ }^{-1-}$ and wild-type mice developed EAE, the OPN ${ }^{-1-}$ animals had significantly less severe disease and a higher percentage of remission. ${ }^{5}$ In our examination of OPN ${ }^{-1-}$ mice, however, we did not find any significant difference in the EAE clinical disease or histopathology from that of $\mathrm{OPN}^{+/+}$mice (Figure 4). One explanation for the difference in EAE clinical disease between our work and that published by Chabas et $\mathrm{al}^{49}$ could be the nature of the OPN deletion. Our $\mathrm{OPN}^{-1-}$ mice $^{43}$ had Exon 1-4 of the OPN gene (OPN-L) removed, whereas the mice used in the Chabas et $\mathrm{al}^{5}$ experiments had Exon 6 of the OPN gene (OPN-R) removed. We note also that another group ${ }^{10}$ had found no difference between $\mathrm{OPN}^{-1-}$ and wild-type mice. Their experiments used an OPN ${ }^{-1-}$ mutant in which they deleted the OPN gene by using homologous recombination 


\section{A Lesion number}

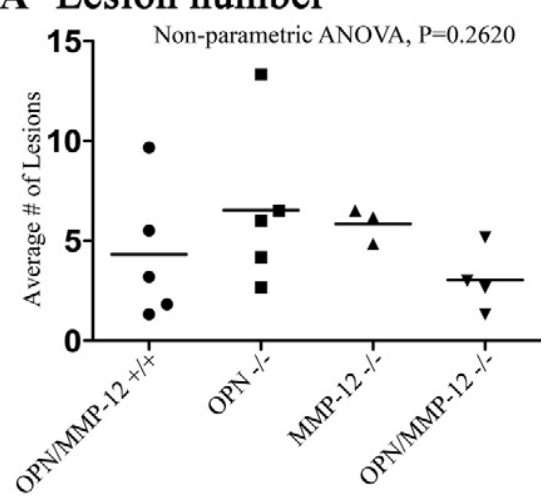

B Inflammation score

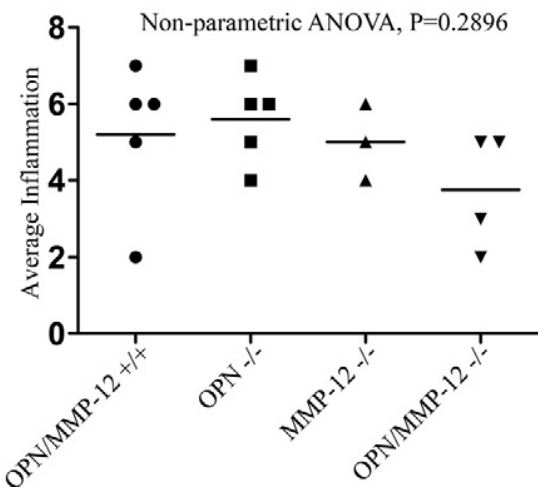

Figure 7. Analyses of the extent of histopathology. A: Inflammatory lesions are similar in number between wild-type, $\mathrm{OPN}^{-/}, \mathrm{MMP}^{-12^{-/-}}$, and OPN MMP-12 $12^{-/-}$mice. B: Inflammation score is also similar across groups although there was a trend toward a lowering in the OPN/MMP- $12^{-/-}$mice. Individual values are plotted and the bar represents the mean for the group. Wild-type, $N=5$; $\mathrm{OPN}^{-1-}, N=5$; $\mathrm{MMP}^{-12^{-/-}}, N=3$; and OPN/MMP$12^{-/-}, N=4$. Nonparametric one-way analysis of variance with Dunn's Multiple Comparison Test was used for statistical analysis.

of strain 129-derived cells and backcrossed 12 generation onto a C57BL/10 background.

Although the exact mechanism of action for OPN in MS and EAE is unknown, there is evidence that OPN may influence cytokine profiles and T cell survival. In cell culture, OPN ${ }^{-1-} \mathrm{T}$ cells showed increased IL-10 secretion and decreased IFN- $\gamma$ and IL-12 secretion after $\mathrm{MOG}_{35-55}$ restimulation. ${ }^{5}$ Jansson et $\mathrm{al}^{9}$ also found that $\mathrm{OPN}^{-1-}$ mice had reduced levels of pro-inflammatory cytokines in the CNS. Hur et $\mathrm{al}^{24}$ found that OPN acted as a $\mathrm{T}$ cell survival factor since in their $\mathrm{OPN}^{-1-}$ mice there was a reduction in T cell apoptosis in vivo and in vitro. In these studies, the possible role of posttranslationally modified OPN was not considered.

As noted earlier, the biological function of OPN is heavily influenced by posttranslational modifications. ${ }^{25}$ Currently, there is very little knowledge about the role proteolytic cleavage of OPN plays in MS and EAE. It is known that cleavage of OPN by MMPs and thrombin can alter OPN's biological functions in other diseases. Thrombin cleavage of OPN results in a cleavage product in which the cryptic SVVYGLR site is exposed; this form of OPN can stimulate the migration of endothelial cells during angiogenesis and is more highly expressed in the synovial fluid of patients with rheumatoid arthritis. ${ }^{27,28}$
MMP-3 and -7 can both cleave OPN, significantly increasing adhesion of tumor cells compared with full length OPN. ${ }^{29}$ They also found that macrophage migration toward cleaved OPN was significantly enhanced compared with full length OPN. For HeLa cells, thrombin cleaved-OPN produced more adhesion compared with MMP-3 cleaved-OPN and this was mediated via the unmasking of new binding sites. ${ }^{29}$ In other inflammatory diseases, such as ulcerative colitis, there is increased OPN and MMP-12 with disease pathogenesis. ${ }^{50}$ In our studies, it would appear that the nonprocessed form of OPN contributes to EAE disease activity since the reduced cleavage of OPN when MMP-12 is absent is correlated with increased EAE severity (Figure 6A). Alternately, the cleaved forms of OPN may be endowed with anti-inflammatory properties and the reduced amounts of these in MMP-12 $12^{-1-}$ mice contribute to disease worsening; however, we were unable to find support for this since two of the sequences (SVVYG and IPVKQ) from MMP-12 processing of OPN elevated the pro-inflammatory cytokine, IL-17. It is probable that other peptides generated from OPN processing by MMP-12 are antiinflammatory. Future studies should be directed toward detailed identification of the fragments of OPN following MMP-12 processing and to address their spectrum of activity and how their accumulation or clearance changes disease severity.

On closer examination of the processing of purified human OPN by MMP-12 (Figure 2), it is noted that there was some breakdown of OPN even in the presence of the MMP inhibitor, BB94. An explanation for the small degree of breakdown of OPN in the presence of BB94 is that insufficient amount of BB94 was added. Moreover, it is possible that MMP-12 may set off a cascade of proteoIytic activity where other proteases (present within the MMP-12 enzyme preparation or in inflamed tissue) are recruited downstream of MMP-12 to further process OPN or its fragments.

In MS and EAE various MMPs are up-regulated during disease. For the most part MMPs are considered detrimental in MS and EAE promoting an inflammatory milieu within the CNS, which ultimately results in demyelination and disease exacerbation. ${ }^{40,51}$ However, we have documented that the up-regulated MMP-12 in EAE is unique in that its absence leads to a worsened EAE disease course compared with wild-type controls $^{31}$ (Figure 6A). We would suggest that the results of this study provide one mechanism to the benefits of MMP-12 in EAE, which is the processing of OPN into less pro-inflammatory forms. It would have been desirable to co-localize MMP-12 and OPN in the EAE spinal cords, since this would be useful in interpreting the accessibility of OPN to MMP-12. However, we were unable to obtain reliable OPN immunohistochemistry in the inflamed spinal cords despite testing a number of OPN antibodies. Moreover, there is the possibility that processing by other proteases or reduced protein translation in our MMP-12 null mice may account for some of our current observations and that this could differentially influence OPN cleavage.

Although the literature has inferred a pro-inflammatory and harmful impact of OPN in MS, it is important to point 
out that OPN can potentially have other effects in the disease. In particular, we are alerted to a study that shows that recombinant OPN stimulates the synthesis of myelin basic protein and promotes myelin sheath formation in mixed cortical cultures from embryonic mouse brain. ${ }^{52}$ The authors suggest that OPN may act as a novel regulator of myelination and remyelination. If so, then antagonizing the effect of OPN may ameliorate neuroinflammation but could have adverse effects on repair of myelin. We have previously implicated a beneficial role for MMP-12 in myelin formation ${ }^{53}$ and whether this is tied to OPN processing remains to be determined.

In conclusion, our results support a disease promoting role of OPN in MS and EAE. Although the complete removal of OPN in null mice did not alter EAE outcomes compared with wild-type controls in our hands, the failure to process elevated OPN protein in the spinal cord of MMP-12 null mice during EAE appears contributory to the worsened phenotype of disease in MMP-12 ${ }^{-1-}$ mice. Although others have proposed inhibiting OPN as therapeutic tools in MS, ${ }^{24,54}$ another strategy that has been suggested by our data are the cleavage of OPN into fragments that appear less harmful, or may even be anti-inflammatory.

\section{References}

1. Steinman L: Multiple sclerosis: a coordinated immunological attack against myelin in the central nervous system. Cell 1996, 85:299-302

2. Frohman EM, Racke MK, Raine CS: Multiple sclerosis: the plaque and its pathogenesis. N Engl J Med 2006, 354:942-955

3. Frohman EM: Multiple sclerosis. Med Clin North Am 2003, 87:867897, viii-ix

4. Hafler DA, Slavik JM, Anderson DE, O'Connor KC, De Jager P Baecher-Allan C: Multiple sclerosis. Immunol Rev 2005, 204:208-231

5. Chabas D, Baranzini SE, Mitchell D, Bernard CC, Rittling SR, Denhardt DT, Sobel RA, Lock C, Karpuj M, Pedotti R, Heller R, Oksenberg JR, Steinman L: The influence of the proinflammatory cyrokine, osteopontin, on autoimmune demyelinating disease. Science 2001, 294:1731-1735

6. Denhardt DT, Noda M, O'Regan AW, Pavlin D, Berman JS: Osteopontin as a means to cope with environmental insults: regulation of inflammation, tissue remodeling, and cell survival. J Clin Invest 2001, 107:1055-1061

7. Keegan BM, Noseworthy JH: Multiple sclerosis. Annu Rev Med 2002, 53:285-302

8. Liu YN, Kang BB, Chen JH: Transcriptional regulation of human osteopontin promoter by C/EBPalpha and AML-1 in metastatic cancer cells. Oncogene 2004, 23:278-288

9. Jansson M, Panoutsakipoulou V, Baker J, Klein L, Cantor H: Attenuated experimental autoimmune encephalomyelitis in Eta-1/osteopontin-deficient mice. J Immunol 2002, 168:2096-2099

10. Blom T, Franzen A, Heinegard D, Holmdahl R: Comment on "The influence of the proinflammatory cytokine, osteopontin, on autoimmune demyelinating disease." Science 2003, 299:1845a

11. Vogt $\mathrm{MH}$, Lopatinskaya L, Smits M, Polman $\mathrm{CH}$, Nagelkerken L: Elevated osteopontin levels in active relapsing-remitting multiple sclerosis. Annals of Neurology 2003, 53:819-822

12. Fakaura H, Ogata A, Kon S, Fukazawa T, Kikuchi S, Tashiro K, Uede $\mathrm{T}$ : Increased osteopontin in cerebrospinal fluid and brains of patients with multiple sclerosis. Presented at the American Neurological Association 128 Annual meeting, San Francisco, 2003, 54 Suppl. 7:s1-94

13. Vogt MH, Floris S, Killestein J, Knol DL, Smits M, Barkhof F, Polman $\mathrm{CH}$, Nagelkerken L: Osteopontin levels and increased disease activity in relapsing-remitting multiple sclerosis patients. J Neuroimmunol 2004, 155:155-160
14. Comabella M, Pericot I, Goertsches R, Espejo C, Castillo M, BlasNavarro C, Montalban X: Plasma osteopontin levels in different clinical subtypes of multiple sclerosis. J Neuroimmunol 2005 158:231-239

15. Chowdhury SA, Lin J, Sadiq SA: Specificity and correlation with disease activity of cerebrospinal fluid osteopontin levels in patients with multiple sclerosis. Arch Neurol 2008, 65:232-235

16. Braitch M, Nunan R, Niepel G, Edwards LJ, Constantinescu CS: Increased osteopontin levels in the cerebrospinal fluid of patients with multiple sclerosis. Arch Neurol 2008, 65:633-635

17. Mochida S, Hashimoto M, Matsui A, Naito M, Inao M, Nagoshi S, Nagano M, Egashira T, Mishiro S, Fujiwara K: Genetic polymorphims in promoter region of osteopontin gene may be a marker reflecting hepatitis activity in chronic hepatitis $\mathrm{C}$ patients. Biochem Biophys Res Commun 2004, 313:1079-1085

18. Niino M, Kikuchi S, Fukazawa T, Yabe I, Tashiro K: Genetic polymorphisms of osteopontin in association with multiple sclerosis in Japanese patients. J Neuroimmunol 2003, 136:125-129

19. Caillier S, Barcellos LF, Baranzini SE, Swerdin A, Lincoln RR, Steinman L, Martin E, Haines JL, Pericak-Vance M, Hauser SL, Oksenberg JR: Osteopontin polymorphisms and disease course in multiple sclerosis. Genes Immun 2003, 4:312-315

20. Hensiek AE, Roxburgh R, Meranian M, Seaman S, Yeo T, Compston DAS, Sawcer SJ: Osteopontin genes and clinical severity of multiple sclerosis. J Neurol 2003, 250:943-947

21. Diaz-Sanchez M, Williams K, DeLuca GC, Esiri MM: Protein coexpression with axonal injury in multiple sclerosis plaques. Acta Neuropathol 2006, 111:289-299

22. Sinclair C, Mirakhur M, Kirk J, Farrell M, McQuaid S: Up-regulation of osteopontin and alphaBeta-crystallin in the normal-appearing white matter of multiple sclerosis: an immunohistochemical study utilizing tissue microarrays. Neuropathol Appl Neurobiol 2005, 31:292-303

23. Koning N, Bo L, Hoek RM, Huitinga I: Downregulation of macrophage inhibitory molecules in multiple sclerosis lesions. Ann Neurol 2007, 62:504-514

24. Hur EM, Youssef S, Haws ME, Zhang SY, Sobel RA, Steinman L: Osteopontin-induced relapse and progression of autoimmune brain disease through enhanced survival of activated T cells. Nat Immunol 2007, 8:74-83

25. Sodek J, Ganss B, McKee MD: Osteopontin. Crit Rev Oral Biol Med 2000, 11:279-303

26. Scatena M, Liaw L, Giachelli CM: Osteopontin: a multifunctional molecule regulating chronic inflammation and vascular disease. Arterioscler Thromb Vasc Biol 2007, 27:2302-2309

27. Hamada Y, Nokihara K, Okazaki M, Fujitani W, Matsumoto T, Matsuo M, Umakoshi Y, Takahashi J, Matsuura N: Angiogenic activity of osteopontin-derived peptide SVVYGLR. Biochem Biophys Res Commun 2003, 310:153-157

28. Yamamoto N, Sakai F, Kon S, Morimoto J, Kimura C, Yamazaki H Okazaki I, Seki N, Fujii T, Uede T: Essential role of the cryptic epitope SLAYGLR within osteopontin in a murine model of rheumatoid arthritis. J Clin Invest 2003, 112:181-188

29. Agnihotri R, Crawford HC, Haro H, Matrisian LM, Havrda MC, Liaw L: Osteopontin, a novel substrate for matrix metalloproteinase-3 (stromelysin-1) and matrix metalloproteinase-7 (matrilysin). J Biol Chem 2001, 276:28261-28267

30. Hou P, Troen T, Ovejero MC, Kirkegaard T, Andersen TL, Byrjalsen I, Ferreras M, Sato T, Shapiro SD, Foged NT, Delaisse JM: Matrix metalloproteinase-12 (MMP-12) in osteoclasts: new lesson on the involvement of MMPs in bone resorption. Bone 2004, 34:37-47

31. Weaver A, Goncalves da Silva A, Nuttall RK, Edwards DR, Shapiro SD, Rivest S, Yong VW: An elevated matrix metalloproteinase (MMP) in an animal model of multiple sclerosis is protective by affecting Th1/Th2 polarization. FASEB J 2005, 19:1668-1670

32. Lindberg RL, De Groot CJ, Montagne L, Freitag P, van der Valk P Kappos L, Leppert D: The expression profile of matrix metalloproteinases (MMPs) and their inhibitors (TIMPs) in lesions and normal appearing white matter of multiple sclerosis. Brain 2001, 124:1743-1753

33. Pagenstecher A, Stalder AK, Kincaid CL, Shapiro SD, Campbell IL: Differential expression of matrix metalloproteinase and tissue inhibitor of matrix metalloproteinase genes in the mouse central nervous system in normal and inflammatory states. Am J Pathol 1998, 152:729-741

34. Cossins JA, Clements JM, Ford J, Miller KM, Pigott R, Vos W, Van der 
Walk P, De Groot CJA: Enhanced expression of MMP-7 and MMP-9 in demyelinating multiple sclerosis lesions. Acta Neuropathologica 1997, 94:590-598

35. Kouwenhoven M, Ozenci V, Gomes A, Yarilin D, Giedraitis V, Press R, Link H: Multiple sclerosis: elevated expression of matrix metalloproteinases in blood monocytes. J Autoimmun 2001, 16:463-470

36. Anthony DCC, Ferguson B, Matyzak MK, Millert KM, Esiri MM, Perry $\mathrm{VH}$ : Differential matrix metalloproteinase expression in cases of multiple sclerosis and stroke. Neuropathol Appl Neurobiol 1997, 23:406-415

37. Agrawal S, Anderson P, Durbeej M, van Rooijen N, Ivars F, Opdenakker G, Sorokin LM: Dystroglycan is selectively cleaved at the parenchymal basement membrane at sites of leukocyte extravasation in experimental autoimmune encephalomyelitis. J Exp Med 2006, 203:1007-1019

38. Folgueras AR, Fueyo A, Garcia-Suarez O, Cox J, Astudillo A, Tortorella $P$, Campestre C, Gutierrez-Fernandez A, Fanjul-Fernandez M, Pennington CJ, Edwards DR, Overall CM, Lopez-Otin C: Collagenase-2 deficiency or inhibition impair experimental autoimmune encephalomyelitis in mice. J Biol Chem 2008, 283:9465-9474

39. Yong VW, Power C, Forsyth P, Edwards DR: Metalloproteinases in biology and pathology of the nervous system. Nat Rev Neurosci 2001, 2:502-511

40. Yong VW, Zabad RK, Agrawal S, Goncalves Dasilva A, Metz LM: Elevation of matrix metalloproteinases (MMPs) in multiple sclerosis and impact of immunomodulators. J Neurol Sci 2007, 259:79-84

41. Agrawal SM, Lau L, Yong VW: MMPs in the central nervous system: where the good guys go bad. Semin Cell Dev Biol 2008, 19:42-51

42. Goncalves DaSilva A, Yong VW: Matrix metalloproteinase-12 deficiency worsens relapsing-remitting experimental autoimmune encephalomyelitis in association with cytokine and chemokine dysregulation. Am J Pathol 2009, 174:898-909

43. Liaw L, Birk DE, Ballas CB, Whitsitt JS, Davidson JM, Hogan BL: Altered wound healing in mice lacking a functional osteopontin gene (spp1). J Clin Invest 1998, 101:1468-1478

44. Shipley JM, Wesselschmidt RL, Kobayashi DK, Ley TJ, Shapiro SD:
Metalloelastase is required for macrophage-mediated proteolysis and matrix invasion in mice. Proc Natl Acad Sci USA 1996, 93:3942-3946

45. Wells JE, Biernaskie J, Szymanska A, Larsen PH, Yong VW, Corbett D: Matrix metalloproteinase (MMP)-12 expression has a negative impact on sensorimotor function following intracerebral haemorrhage in mice. Eur J Neurosci 2005, 21:187-196

46. Giuliani F, Metz LM, Wilson T, Fan Y, Bar-Or A, Yong VW: Additive effect of the combination of glatiramer acetate and minocycline in a model of MS. J Neuroimmunol 2005, 158:213-221

47. Larsen PH: Matrix metalloproteinases: clearing the way for myelin formation in the CNS. Neuroscience. Calgary, University of Calgary, 2004, pp 1-167

48. DaSilva AG, Yong VW: Expression and regulation of matrix metalloproteinase-12 in experimental autoimmune encephalomyelitis and by bone marrow derived macrophages in vitro. J Neuroimmunol 2008, 199:24-34

49. Rittling SR, Matsumoto HN, McKee MD, Nanci A, An XR, Novick KE, Kowalski AJ, Noda M, Denhardt DT: Mice lacking osteopontin show normal development and bone structure but display altered osteoclast formation in vitro. J Bone Miner Res 1998, 13:1101-1111

50. Masuda H, Takahashi Y, Asai S, Takayama T: Distinct gene expression of osteopontin in patients with ulcerative colitis. J Surgical research 2003, 111:85-90

51. Rosenberg GA: Matrix metalloproteinases and neuroinflammation in multiple sclerosis. Neuroscientist 2002, 8:586-595

52. Selvaraju R, Bernasconi L, Losberger C, Graber P, Kadi L, AvellanaAdalid V, Picard-Riera N, Van Evercooren AB, Cirillo R, Kosco-Villbois M, Feger G, Papoian R, Boschert U: Osteopontin is upregulated during in vivo demyelination and remyelination and enhances myelin formation in vitro. Mol Cell Neurosci 2004, 25:707-721

53. Larsen PH, DaSilva AG, Conant K, Yong VW: Myelin formation during development of the CNS is delayed in matrix metalloproteinase- 9 and -12 null mice. J Neurosci 2006, 26:2207-2214

54. Stromnes IM, Goverman JM: Osteopontin-induced survival of T cells. Nat Immunol 2007, 8:19-20 